\title{
Hypoglycemia Controlled by Prednisone in an Occult Insulinoma or a Nesidioblastosis
}

\author{
Annelie Kérékou ${ }^{1,2}$, Siham El Aziz², Alihonou Dédjann,2, Asma Chadli², Ahmed Farouqi² \\ ${ }^{1}$ Endocrinology, Metabolism and Nutrition Department, CNHU-HKM, Cotonou, Benin \\ ${ }^{2}$ Endocrinology, Diabetology and Metabolic Diseases Department, Ibn Rochd University Hospital Center, Casablanca, Morocco \\ Email: kerekouannelie@yahoo.fr
}

How to cite this paper: Kérékou, A., El Aziz, S., Dédjan, A., Chadli, A. and Farouqi, A. (2019) Hypoglycemia Controlled by Prednisone in an Occult Insulinoma or a Nesidioblastosis. Open Journal of Endocrine and Metabolic Diseases, 9, 69-73. https://doi.org/10.4236/ojemd.2019.96007

Received: February 2, 2019

Accepted: June 9, 2019

Published: June 12, 2019

Copyright (c) 2019 by author(s) and Scientific Research Publishing Inc. This work is licensed under the Creative Commons Attribution International License (CC BY 4.0).

http://creativecommons.org/licenses/by/4.0/

\begin{abstract}
Insulinoma is a pancreatic endocrine tumor lower in size than $20 \mathrm{~mm}$ in $80 \%$ of the cases and his treatment is chirurgical. However, in certain circumstances such as an occult location or circumstances of metastases, medical treatment is called for. Observation: A 29 years old patient with no specific pathological antecedents has presented severe hypoglycemia mainly in the morning. A patient was in a generally good condition. The fasting test revealed an inappropriate secretion of insulin at a venous glycemia of $0.35 \mathrm{~g} / \mathrm{l}$; which was corroborated by Turner index and altered glucose insulin index that we calculated. Moreover, the $8 \mathrm{~h}$ cortisolemia was normal at $90.13 \mathrm{ng} / \mathrm{l}$, the TSH was normal at $1.44 \mu \mathrm{ui} / \mathrm{l}$, anti-insulin antibodies were negative at 6.7 $\mathrm{U} / \mathrm{l}$; the search of hypoglycemic sulfonamides was negative. Morphologically, she had three pancreatic tomodensitometry these were normal. She also had echo-endoscopy which showed a normal pancreas. The surgical exploration with preoperative echo is advised only after surgeon's assessment when the technical conditions are not put together. The diagnosis of the occult insulinoma or of nesidioblastosis was retained. The medical treatment was retained. Due to the unavailability of diazoxide in our pharmacies and the high cost of analogs of somatostatine, she was provided with prednisone 0.5 $\mathrm{mg} / \mathrm{kg} / 24 \mathrm{~h}$ which was $40 \mathrm{mg} /$ day after common agreement. The evolution was favorable. Conclusion: It should be noticed that medical treatment can be suggested if insulinoma is not localized. This observation proves that the localization of the insulinoma can be unsuccessful. It should also be noticed that our experience is the fourth described in literature, where hypoglycemia in insulinomas is controlled by prednisone.
\end{abstract}

\section{Keywords}

Hypoglycemia, Insulinoma, Nesidioblastosis, Prednisone 


\section{Introduction}

Insulinoma is a pancreatic endocrine tumor lower in size than $20 \mathrm{~mm}$ in $80 \%$ of the cases and is clinically manifested by hypoglycemias. Its incidence is 3 to 5 cases for millions of inhabitants per year. Its treatment is surgical and consists of exeresis of the tumor as soon as it is localized. However, in certain circumstances such as an occult location or circumstances of metastases, medical treatment is called for. We report this case to show the difficulty sometimes related to localization of insulinoma and the possibility of relieving patients with prednisone in case of unsuccessful localization.

\section{Observation}

We report a case of a 29 years old patient with no specific pathological antecedents nor diabetic heredity nor any notion of specific drug intake. For three years, she has presented severe hypoglycemia mainly in the morning, preprandial, when waking up, away from meals and upon physical effort with weight gain of 12 kilo. The symptomatology ranges from neurovegetative signs to hypoglycemic coma requiring hospitalization in emergency twice before her admission to the department.

The exam reveals a patient in good general condition, aware, normotensive at $110 / 80 \mathrm{mmHg}$ with no other anomalies.

Biologically, the fasting test revealed an inappropriate secretion of insulin at a venous glycemia of $0.35 \mathrm{~g} / \mathrm{l}$; which was corroborated by Turner index and altered glucose insulin index that we calculated (Table 1). Moreover, the $8 \mathrm{~h}$ cortisolemia was normal at $90.13 \mathrm{ng} / \mathrm{l}[62-194]$, the TSH was normal at $1.44 \mu \mathrm{ui} / \mathrm{l}$ [0.47 - 4.46], anti-insulin antibodies was negative at $6.7 \mathrm{U} / \mathrm{l}(<10)$; the search of hypoglycemic sulfonamides was negative. The hepatic assessment and the renal one were normal.

Morphologically, she had three abdominal computed tomography (Figure 1) these were normal ( 1 before her admission and two at 6-month interval in our department). She also had echo-endoscopy which showed a normal pancreas and gastritis with no helicobacter when anatomopathologically examined. The surgical exploration with preoperative echo is advised only after surgeon's assessment when the technical conditions are not put together. Octreoscan is also always discussed for the localization of the tumor, however, due to its sensitiveness and specifity, it was not carried out, nor were the artery calcic perfusion tests. The diagnosis of the occult insulinoma or of nesidioblastosis was retained.

The medical treatment was retained to relieve the patient with respect to the

Table 1. Turner index and altered glucoses insulin index.

\begin{tabular}{ccccc}
\hline $\begin{array}{c}\text { glycemia } \\
(\mathrm{g} / \mathrm{l})\end{array}$ & $\begin{array}{c}\text { Insulinemia } \\
(1.9-23 \\
\mathrm{mUI} / \mathrm{l})\end{array}$ & $\begin{array}{c}\text { peptide C } \\
(1.1-4.4 \mathrm{mg} / \mathrm{l})\end{array}$ & $\begin{array}{c}\text { Altered glucoses/insulin } \\
\text { index }(<53.6)\end{array}$ & $\begin{array}{c}\text { Turner index } \\
(<30)\end{array}$ \\
\hline 0.34 & 6.2 & 2.10 & 223 & 155 \\
\hline
\end{tabular}




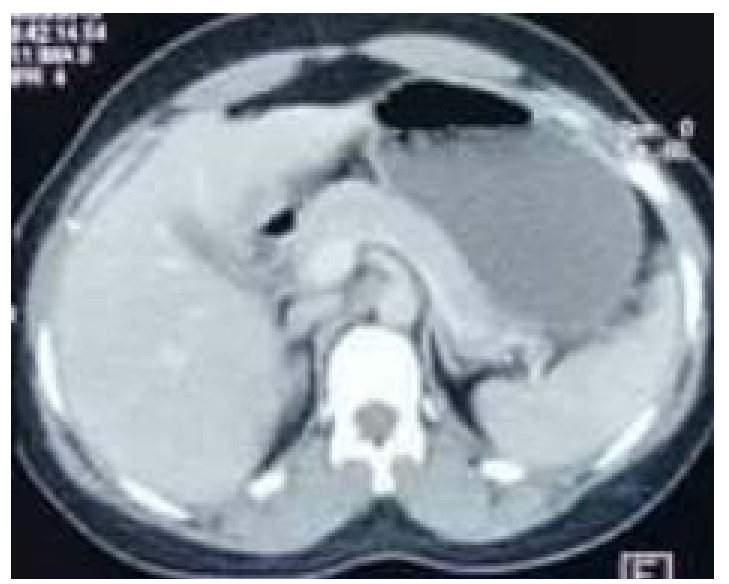

Figure 1. Pancreas scanner.

available means. Due to the unavailability of diazoxide in our pharmacies and the high cost of analogs of somatostatin, she was provided with prednisone 0.5 $\mathrm{mg} / \mathrm{kg} / 24 \mathrm{~h}$ which was $40 \mathrm{mg} /$ day after common agreement. The evolution was marked by the cease of perfusions of glucose serum at the end of the first week. The patient was declared outgoing under prednisone in addition to adjuvant treatment and dietetic measure. The control carried out after 1 month showed that the fasting blood glucose was $0.51 \mathrm{~g} / \mathrm{L}$ and she reported that she took 5 meals a day with a neat improvement in her life quality. She did not show up for her exam after 3 months. Upon her visit after 6 months, the glycemia was 0.59 $\mathrm{g} / \mathrm{l}$ with a decrease in weight that became $70 \mathrm{~kg} \cdot \mathrm{s}$ and she informed us that she had no more hypoglycaemia. She stated that she took 3 meals per day with a noticeable improvement in life quality. A visit after 8 months showed that fasting blood glucose was $0.69 \mathrm{~g} / \mathrm{l}$ with a steady weight. She was normotensive with a normal phosphocalcic assessment.

\section{Discussion}

Insulinoma diagnosis is biological but its localization by modern means of imagery can be unfruitful. Thus, in $10 \%$ of cases, insulinomas are not localized [1]. They are defined as occult.

Nesidioblastosis is also evoked here though it did not undergo digestive surgery in the past [2]. It is behind endogenous hyperinsulinism in adults in less than $5 \%$ of the cases [3].

As far as the test of localization is concerned, the surgical exploration has no longer been realized because of the technical tray. Let's say in fact this surgical exploration is negative in ten percent of the case according to the literature [1].

In the same way we have not been able to realize the following explorations but their sensibility does not exceed that of the echo-endoscopy. Thus, Octreoscan sensibility is fifty percent and it may be coupled with single photon emission computed tomography (SCPECT-CT) [4]. The sensibility of Fluorine-18-L Dihydroxyphenylalanine (18F-DOPA) scintigraphy is sixty five percent. Coupled 
with SPECT CT, the sensibility is ninety percent for the insulinoma and it also allows to identify nesidioblastosis [4]. The arteriography realized after pancreatic vessels catheterization after injection of calcium gluconate has almost a sensibility of seventy percent and identifies the tumor in ninety percent of cases [5] [6]. The scintigraphy using Glucagon-like 1 receptor (GLP1) agonist has been developed and allows achievement of good results as shown by Chris ER et al. [7].

It should be noticed that medical treatment can be suggested if insulinoma is not localized, if the patient refuses surgery or if their general condition does not allow it or even in case of inextirpable metastatic disease. It controls hypoglycemia symptoms in $50 \%$ to $60 \%$ of the cases [8]. The drugs used in efficiency order are diazoxide at 300 to $600 \mathrm{mg} / \mathrm{day}$, octreotide and corticoids in case of failure of the former two.

Thus GV Gill and al treated 40 insulinomas surgery being refused for diverse reasons and they noticed that $59 \%$ were totally controlled for symptoms against $38 \%$ who presented occasional symptoms and $3 \%$ of failure [9]. VEZZOZI and al treated 17 patients suffering from insulinoma with octreotide $(100 \mu \mathrm{g}$ in sub-cutaneous) and they observed a biological response in 58\% [10]. The use of corticoids is based on their side effects mainly insulin-resistance through the decrease of peripheral use of glucose, the increase of hepatic neoglucogenesis. In literature, the first case of malignant insulinoma whose hypoglycemia was controlled by glucocorticoids was prescribed by Sadoff and al in 1975 [11]. The second case was reported by Debreceni and Meszaros in 1987 [12] and the third case by Jan Novotny in 2005 [13]. The latter case was of a 55 years old woman who presented severe hypoglycemia due to metastatic insulinoma for which she underwent chemotherapy, radiotherapy and lanreotide $30 \mathrm{mg} /$ week in combination with interferon alpha 2, diazoxide $100 \mathrm{mg}$ /day but unsuccessfully. She then was provided with prednisone $60 \mathrm{mg} /$ day with an improvement of the symptoms after degression up to $2.5 \mathrm{mg} /$ day.

\section{Conclusion}

This observation proves that the localization of the insulinoma can be unsuccessful. It should also be noticed that our experience is the fourth described in literature, where hypoglycemia in insulinomas is controlled by prednisone. We can maintain that the usage of corticoids to control hypoglycemia in insulinoma or in nesidioblastosis is possible in case of failure of diazoxide, analogs of somatostatin or in case of their non-availability. The specification of these two conditions is required because, although the obtained results are encouraging, the side effects of corticoids should be taken into consideration for long term use.

\section{Conflicts of Interest}

The author declares no conflicts of interest regarding the publication of this paper. 


\section{References}

[1] Abboud, B. and Boujaoude, J. (2008) Occult Sporadic Insulinoma: Localization and Surgical Strategy. World Journal of Gastroenterology, 14, 657-665. https://doi.org/10.3748/wjg.14.657

[2] Anlauf, M., Wieben, D., Perren, A., et al. (2005) Persistent Hyperinsulinic Hypoglycemia in 15 Adults with Diffuse Nesidioblastosis. American Journal of Surgical Pathology, 29, 524-533. https://doi.org/10.1097/01.pas.0000151617.14598.ae

[3] Anlauf, M., Bauersfeld, J., Raffel, A., Koch, C.A., Henopp, T., Alkatout, I., et al. (2009) Insulinomatosis: A Multicentric Insulinoma Disease That Frequently Causes Early Recurrent Hyperinsulinemic Hypoglycemia. American Journal of Surgical Pathology, 33, 339-346. https://doi.org/10.1097/pas.0b013e3181874eca

[4] Kauhanen, S., Seppanen, M., Minn, H., et al. (2007) Fluorine-18-L Dyhydroxyphenylalanine (18-F-DOPA) Position Emission Tomography as a Tool to Localize an Insulinoma or Beta-Cell Hyperplasia in Adult Patients. Journal of Clinical Endocrinology \& Metabolism, 92, 1237-1244. https://doi.org/10.1210/jc.2006-1479

[5] Jackson, J.E. (2005) Angiography and Arterial Stimulation Venous Sampling in the Localization of Pancreatic Neuroendocrine Tumors. Best Practice \& Research Clinical Endocrinology \& Metabolism, 19, 229-239. https://doi.org/10.1016/j.beem.2004.10.002

[6] Guettier, J.M., Kam, A., Chang, R., et al. (2009) Localization of Insulinomas to Regions of Pancreas by Intrarterial Calcium Stimulation: The NIH Experience. Journal of Clinical Endocrinology \& Metabolism, 94, 1074-1080.

https://doi.org/10.1210/jc.2008-1986

[7] Christ, E.R., Wild, D., Braendle, M., et al. (2009) Glucagon-Like 1 Receptor Imaging for the preoperative Localization of Insulinomas (OR25-1). $1^{\text {st }}$ Annual Meeting of Endocrine Society, Washington DC.

[8] Cazabat, L. and Chanson, P. (2009) Hypoglycémie et insulinome. Annales d'Endocrinologie, 70, S2-S11. https://doi.org/10.1016/s0003-4266(09)72470-9

[9] Gill, G.V., Rauf, O. and Macfalane, I.A. (1997) Diazoxide Treatment for Insulinoma: A National UK Survey. Postgraduate Medicine, 73, 640-641. https://doi.org/10.1136/pgmj.73.864.640

[10] Vezzosi, D., Bennet, A., Rochaix, P., et al. (2005) Octreotide in Insulinoma Patients: Efficacy on Hypoglycemia, Relationships with Octreoscan Scintigraphy and Immunostaining with Anti-sst2A and Anti-sst5 Antibodies. European Journal of Endocrinology, 5, 757-767. https://doi.org/10.1530/eje.1.01901

[11] Sadoff, L., Gordon, J. and Goldman, S. (1975) Amelioration of Hypoglycaemia in a Patient with Malignant Insulinoma during the Development of the Ectopic ACTH Syndrome. Diabetes, 24, 600-603. https://doi.org/10.2337/diab.24.6.600

[12] Debreceni L and Meszaros, I. (1987) Persistent Hypoglycaemia Due to Hyperinsulinemia, Hypoglucagonemia and Mild Adrenal Insufficiency. Experimental and Clinical Endocrinology, 90, 221-226. https://doi.org/10.1055/s-0029-1210693

[13] Novotny, J., Janku, F., Mares, P. and Petruzelka, L. (2005) Symptomatic Control of Hypoglycaemia with Prednisone in Refractory Metastatic Pancreatic Insulinoma. Support Care Cancer, 13, 760-762. https://doi.org/10.1007/s00520-005-0840-5 